\title{
El Dios mortal. ¿Implica la globalización una progresiva desaparición de los Estados?
}

\section{The Mortal God. Does Globalization Imply "the End of the State"?}

\author{
Ramón Máiz ${ }^{1}$ \\ Universidad de Santiago de Compostela (España)
}

Recibido: 29-02-16

Aprobado: 09-07-16

\section{Resumen}

El artículo discute la tesis postmoderna de que la globalización implica el progresivo desmantelamiento del Estado. Desde una perspectiva estratégicorelacional y neo-institucionalista histórica se trata de mostrar, analizando las principales continuidades y descontinuidades entre el Estado regulador clásico y el nuevo Estado eficiente y competitivo del neoliberalismo, que los Estados siguen desempeñando un papel clave en la reproducción ampliada del capital. Se sostiene que el vocabulario de la "desregulación" oscurece los procesos de estatismo neoliberal autoritario que tienen lugar en la actualidad.

Palabras-clave: Estado, globalización, soberanía, neoliberalismo, Imperio.

\footnotetext{
${ }^{1}$ (ramon.maiz@usc.es) Ramon Maiz is professor of Political Science at the University of Santiago de Compostela (Spain). His main fields of research are comparative nationalist and ethnic mobilizations and political theory. He has published recently in journals as Regional and Federal Studies, Nationalism and Ethnic Politics, Journal of Political Ideologies, Studies in Ethnicity and Nationalism and Nations and Nationalism. Some of his books are: with W. Safran Identity and Territorial Autonomy in Plural Societies London: Frank Cass, 2000; The Construction of Europe, Democracy, and Globalization USC. 2001; Democracy, Nationalism and Multiculturalism (coedited with Ferran Requejo) Routledge: London, 2004; Ethnicité et Politique (coedited with Jean Tournon) L'Harmattan: Paris, 2006. His last books are The Inner Frontier Bruxelles: Frank Cass, 2013; and with Tiffany Shellam Rosendo Salvado and the Australian Aboriginal World ( 2015). He is the director of the Research Group in Politics at the University of Santiago de Compostela, member of the board of the IPSA Standing Committee on Ethnicity and Politics, member of academic board of FLACSO (SPAIN) and coordinates, with Michael Keating, the Scotland- Galicia- Wales Network On Devolution. He is member of the editorial board of Nationalism and Ethnic Politics and Pôle Sud. For more information please see Academia, Researchgate or his personal web page: http://webspersoais. usc.es/persoais/ramon.maiz/.
} 


\begin{abstract}
This paper discusses the postmodern thesis of the end of the state due to the increasing processes of world globalization. From a strategic-relational and neoinstitutionalist perspective the author tries to show, analysing the main changes and differences between the classic regulatory state and the present neoliberal state, that the states system continue to develop key tasks and functions in the reproduction of capitalist mode of production. In fact, the vocabulary of deregulation obscures the re-regulation processes at stake in the new emergent forms of authoritarian liberal neowelfarism or liberal neoestatism.
\end{abstract}

Key-words: State, Globalization, Sovereignty, Neoliberalism, Historical Institutionalism.

"This is the Generation of that great LEVIATHAN, or rather (to speake more reverently) of that Mortal God, to which we owe under The Inmortal God, our peace and defence"

Thomas Hobbes, Leviathan 1651

“Je m'en vais, mais l'État demeurera toujours"

Louis XIV, 1715

\title{
1. Una cuestión previa: concepto, funciones y proceso de construcción de los Estados
}

La tesis que defenderemos en este texto es que los argumentos que predican la desaparición o crisis del Estado en la era de la globalización neoliberal tienen su raíz en un concepto teórica e históricamente implausible, que desatiende y tergiversa aspectos centrales de la estatalidad tanto en lo que se refiere a la estructura institucional como a la acción política. En las páginas que siguen proponemos una perspectiva a la vez neoinstitucionalista histórica y estratégica relacional para proceder a la crítica de los apresurados certificados de defunción de este "dios mortal" que menudean en nuestros días.

El concepto de Estado, en su sentido moderno, define el complejo y variado proceso de construcción ("state building") de un sistema de dominación específico, caracterizado por el monopolio institucional del poder político y de la violencia legítima. Esta definición implica algunas precisiones: 1) a pesar de que el término "Estado" se encuentra presente en muy diferentes contextos históricos, posee significados conceptuales diversos y se refiere, en no pocas ocasiones, a realidades muy diferentes a la del Estado en su sentido estricto. El término "Estado" previo a las revoluciones del mundo moderno designa, en rigor, formas preestatales de dominación 
("ciudades-Estado", "Estado del Renacimiento", "Estado Moderno", "Estado absolutista" etc.), caracterizadas por la ausencia del rasgo conceptual decisivo que consideramos indispensable: el monopolio del poder político (legislativo, judicial, ejecutivo, fiscal, militar), en una instancia organizativo-institucional que se escinde y se autonomiza sobre la sociedad civil; 2) el Estado no constituye el resultado natural y lógico de la evolución histórica de las formas políticas, un inevitable y teleológico punto de llegada predeterminado de antemano desde el inicio de los tiempos. Por el contrario, durante siglos, las monarquías territoriales centralizadas compitieron con fórmulas muy distintas de organización del poder político: ciudades-Estado, el Papado, los Imperios, dominios y señoríos descentralizados etc. El Estado surgió como resultado eventual y contingente de un proceso, complejo y multicausal, evolutivo, adaptativo y competitivo, a lo largo del cual se mostró finalmente como la fórmula más apta para gobernar un territorio amplio con población numerosa y mantener un ejército permanente; 3) la progresiva instauración de la nueva lógica dominante de la estatalidad y la posterior triple ruptura conceptual (Soberanía), económica (Capitalismo) y política (Revolución) entre el mundo de los Estados y de las formas preestatales de dominación, no debe impedir dar cuenta, sin embargo, del hecho de que parte de los procesos de construcción estatal se inicia intelectual, social y políticamente a partir de elementos ya presentes con anterioridad en el seno de la lógica previa tardofeudal (Monarquías centralizadas, Monarquías absolutas). Por otra parte, se trató siempre de un proceso tentativo e incompleto, las pretensiones de "soberanía" y el monopolio completo del poder político en un territorio fueron siempre aspiraciones ideales y nunca realidades cristalizadas definitivamente. El proceso de concentración del poder político resultó duramente contestado, se vio sometido a continuos avances y retrocesos, en razón de múltiples conflictos y desafíos internos y externos. Tampoco existieron ni una vía única y ni un estadio final, uniformes y homogéneos, de configuración estándar del Estado, variando mucho según los países y las coyunturas históricas, tanto en sus capacidades estatales efectivas (burocráticas, militares, fiscales, de orden público etc.), como en su decantación en diferentes regímenes políticos (monárquicos o republicanos, civiles o militaristas, democráticas o autoritarias etc.).

Desde una perspectiva deudora del evolucionismo y el neoinstitucionalismo histórico, el Estado es, en su sentido conceptual estricto, un sistema político adaptativo y cambiante, un abigarrado y emergente conjunto de aparatos, procedimientos, reglas y organizaciones, estratégicamente selectivas de preferencias e identidades. Estas instituciones destacan por su capacidad de facilitar la toma de decisiones, hacerlas cumplir y aceptar como legítimas por la ciudadanía de un territorio determinado, respaldarlas por el monopolio de la 
coacción y presentarlas ideológicamente como realizaciones de las ideas del Bien común y/o el Interés nacional. Pero el Estado no es ni ha sido nunca un aparato neutral y completamente independiente respecto a la sociedad que trata de regular, sino que resulta, a su vez, conformado por ella y actúa con selectividad estratégica, favoreciendo unos intereses sociales determinados y unas identidades individuales (ciudadanía) y colectivas (nación) y marginando otras posibles preferencias y otras alternativas identitarias, a través de sus políticas públicas y sus diseños institucionales. El Estado es una relación social que depende en última instancia de una correlación de fuerzas políticas específica. Por lo tanto, en lugar de un ente institucional unificado y suturado de una vez para siempre por el principio de la soberanía, constituye el resultado contingente de las luchas políticas por la hegemonía (la dirección intelectual y moral de un país) que se inscriben - con sus derrotas y sus victorias- en su propia materialidad institucional. Desde estas instituciones el Estado ejerce, mediante diversos incentivos selectivos, un poder infraestructural de penetración, organización y redistribución sobre la sociedad, en un territorio determinado y al servicio de diferentes clases sociales (Poulantzas 1978, Mann, 1984, Jessop 2016).

Por todas estas razones resulta conveniente adoptar una perspectiva relacional y estratégica, pues el Estado moderno no se presenta como una estructura estática y aislada, sino como el resultado, eventual y muy variado, de un proceso de evolución, competición y adaptación, causado tanto por shocks exógenos (económicos, políticos o bélicos), como por movilizaciones políticas y conflictos endógenos. Este proceso multicausal, muy diferente en sus ritmos, características y cristalizaciones según los países, condensa, en grado diverso, el efecto de varios factores. Éstos últimos, en cuanto variables explicativas, diferenciadas y a la vez interdependientes, se combinan y explican, en mayor o menor medida, cada Estado concreto, dependiendo de los distintos contextos y ecologías en las que éste se desarrolla.

El proceso de construcción de los Estados (State-building) puso en movimiento una nueva lógica evolutiva y adaptativa, desigual y muy variada según los países, con temporalidades diferenciadas por países y con avances y retrocesos, nunca lineal, pero que acabaría por cristalizar en una discontinuidad radical con el pasado. Esta lógica se desarrolla mediante la intervención de los seis factores ya mencionados; veámoslos muy brevemente:

1.- El punto de partida del proceso de creación de los Estados fué la guerra en su doble vertiente: internacional, entre unidades políticas para adquirir territorio y recursos, e interior o civil para apaciguar las poblaciones frente a las sublevaciones internas y permitir el control fiscal, administrativo y de orden público del territorio. En un mundo en guerra solo sobrevivieron las unidades 
políticas más aptas para poner en pie un ejército permanente numeroso, bien pertrechado y leal. En esta suerte de lucha por la vida en un escenario bélico, el Estado territorial se impondrá a otros competidores como las ciudades Estado, los ducados descentralizados (como el de Borgoña) o los Imperios tardofeudales y el Papado.

2.- La necesidad de organizar un ejército permanente no solamente requirió una dimensión territorial amplia que permitiera reclutar hombres y extraer recursos, precisó además administración, esto es, Burocracia y Hacienda Pública capaz de organizar el territorio, cobrar impuestos, administrarlos y legitimarlos: Gobierno, Hacienda y Representación parlamentaria constituyeron tres elementos básicos, que se añadieron a la tradicional impartición de Justicia, que se acompañarán de la producción del derecho igual, obligatorio y coactivamente impuesto en todo el territorio y la progresiva derogación de los privilegios y exenciones particulares.

3.- Los Estados crearon los mercados nacionales: unificaron el derecho, acuñaron la moneda, unificaron precios, eliminaron obstáculos como los privilegios, los impuestos y rentas locales o la regulación gremial de los oficios, mantuvieron expeditos los caminos para el transporte a salvo de delincuentes, crearon infraestructuras que mejoraron el comercio y la producción, abrieron espacios coloniales que beneficiaron a las clases comerciales, otorgaron monopolios que garantizaban apoyos clientelares, y desarrollaron la legislación mercantil, civil y penal sin la cual los mercados no podrían existir. En este proceso, el papel de las ciudades y la clase burguesa, sus intereses y sus ideologías resulta clave tanto como núcleos de acumulación y concentración intensivas de capital, como por su participación en la construcción de redes de circulación de capital y su conversión en centros progresivamente dependientes del derecho, el ejército y la dominación de los Estados.

4.- Los elementos anteriores contribuyen a controlar, dominar y, en rigor, producir políticamente el territorio del Estado mediante la soberanía a la vez interna (monopolio del poder político y la violencia legítima) y externa (reconocimiento como sujeto competitivo en el ámbito internacional del sistema de Estados como unidades equivalentes). La creación de fronteras ciertas y estables es el trasunto de la organización militar, policial, burocrática y financiera del Estado en una cadena que anuda de modo indisoluble territorio, población y soberanía. 
5.- La población de un (amplio) territorio proporciona, por una parte los recursos de hombres necesarios para el ejército y los recursos económicos, dinero y vituallas para una logística competitiva. Por otra parte esto demanda el cobro de impuestos y la creación de una Hacienda Pública (y la correlativa eliminación de haciendas locales, privilegios y exenciones), lo cual reenvía, a su vez, a la génesis de legitimación de los mismos mediante órganos representativos (cortes, parlamentos y juntas), a la negociación de concesiones de derechos, y a los conflictos de la ciudadanía y sus derechos individuales. Pero también a las luchas políticas por las libertades, por la ampliación de derechos de propiedad, libertad, la igualdad y la representación política (tránsito del sufragio censitario al universal) y su aseguramiento constitucional. Al hilo de todo ello, la población del territorio del Estado comienza a ser disciplinada políticamente no solo como pueblo del Estado (conjunto de ciudadanos individuales), sino como Nación (Comunidad): una producción mítico simbólica y política de la identidad común, una lengua, una historia, una narrativa compartida, un nosotros comunitario que separa lo propio de lo ajeno, el amigo del enemigo. Este proceso es clave tanto para la legitimación de la dominación cuanto para los sacrificios fiscales y militares.

6.- Por último, un factor decisivo del proceso de construcción estatal son las ideas pues el concepto de Estado para existir requiere también de condiciones intelectuales de posibilidad, esto es, debe ser pensado, imaginado, elaborado teóricamente con conceptos como "soberanía", "derecho", "constitución", "representación" etc. El Estado produce y es producido mediante ideas tanto como desde procesos materiales institucionales y económicos. Además, el poder ideacional, la capacidad de los actores individuales y colectivos de influenciar los valores, creencias y principios de otros actores, desempeña un papel fundamental en el desarrollo de la estatalidad. La lucha y el antagonismo entre proyectos de estatalidad, ideas e ideologías constituyen una dimensión capital de la emergencia y cristalizaciones hegemónicas varias del Estado moderno.

\section{Funciones, evolución y variaciones del Estado en el modo de producción capitalista: del Estado liberal al Estado de Bienestar.}

La construcción del Estado en su sentido estricto, esto es, como monopolio del poder político y la violencia legítima que se autonomiza y se separa de la sociedad civil, implica la emergencia y generalización de una lógica nueva, frente al mundo preeestal, que, sin embargo, no es 1) ni homogénea para todos los casos, 2) ni coetánea en todos los países, 3) ni tampoco exclusiva, sino que convive durante cierto tiempo con residuos preestatales. 
En apretada síntesis, el proceso de construcción de los Estados interrelaciona tres elementos fundamentales: 1) las clases sociales propias del modo de producción capitalista, 2) los Estados en cuanto relaciones sociales $\mathrm{y}$, a la vez, ente institucionales autónomos (coacción extraeconómica) y 3) las Naciones como comunidades culturales políticamente construidas desde o contra los Estados. Y lo hace mediante, al menos, cuatro dinámicas sucesivas y, la vez, en alguna medida superpuestas y nunca lineales: 1) las movilizaciones revolucionarias de ruptura con el Antiguo Régimen, 2) la construcción organizativa, institucional y mítico-simbólica del Estado nacional, 3) los desarrollos desiguales del Estado Liberal democrático, constitucional representativo y la ampliación de la ciudadanía; y 4) la del Estado regulador de la economía y de Bienestar (Mann 1993, Rokkan 1999)

Solamente después de la doble revolución inglesa del siglo XVII, con el nacimiento del capitalismo, comienza a emerger un Estado que acumula y reorganiza el poder político antes disperso, de ahí que sea en la obra de Hobbes y no en la de Bodin donde el concepto de soberanía alcance su significado auténticamente moderno: no simplemente como posición de superioridad jerárquica de unos de los poderes (el monarca) sobre otros, a los que está obligado a respetar, sino en calidad de único poder político que existe en un territorio dado. "Transferir todo el poder y toda la fuerza a un hombre o una asamblea de hombres" (Hobbes), esto es, a una institución que monopoliza el poder político y que se puede articular ora como República, ora como Monarquía. A partir de este momento el Estado comienza a reformularse como Estado-Nación, mediante variados e interrelacionados procesos de state-building y nation-building. Según el esquema seminal de Rokkan, estos procesos se estructuran en un modelo básico de tensión centro-periferia de cuatro dimensiones que se co-implican; a saber: 1) violencia (ejército, orden público, administración), 2) economía (producción y distribución), 3) derecho (constitución, legislación positiva, representación) y 4) cultura (mitos, símbolos, lenguas). Procesos de interacción y variación que, a su vez, dependen de cuatro variables explicativas fundamentales: 1) configuración secular/religiosa, 2) unificación/diferenciación lingüística, 3) dependencia/independencia de la red de ciudades, y 4) concentración/dispersión de la propiedad de la tierra. En una perspectiva diacrónica es posible, además, establecer una secuencia de diversas fases en el mencionado proceso de construcción del Estado: I) penetración territorial (sistema fiscal, orden público, resolución judicial de conflictos, unificación económico-política de las elites); II) estandarización nacional: militar, cultural y lingüística (servicio militar y escuela obligatoria, medios de comunicación de masas, vías de comunicación: carreteras, ferrocarriles, correos , telégrafos etc.); (III) participación y representación política (extensión de los derechos de sufragio universal, derechos políticos, formación de partidos 
políticos, elecciones libres y competitivas, regulación de la ciudadanía); y IV) redistribución de recursos (servicios de bienestar, aseguramiento, ciudadanía social, políticas redistributivas, fiscalidad progresiva). La autonomía del Estado, su capacidad de conformar la sociedad (crear mercados y naciones) no debe hacernos olvidar el condicionamiento social de las instituciones estatales: el conflicto de clase constituyó siempre el clivaje fundamental en el proceso de democratización y, a su vez, el ingreso de las clases populares en el escenario político nacional supuso un aspecto central de la construcción de los Estados nacionales en Europa (Bartolini 2005).

Ahora bien, como Montesquieu supo ver con lucidez aquella "supresión de poderes intermedios", una tamaña concentración, inédita, de medios de dominación, podría muy bien hacer "de los ingleses uno de los pueblos más esclavos de la tierra". Será este monopolio del poder político y esta separación del Estado sobre la sociedad civil la que motivará las demandas y conflictos para construir un sistema nuevo de legitimidad, mediante el que las nuevas clases dominantes de propietarios pudieran controlar y participar, con garantías individuales y políticas, en la toma de decisiones y la elaboración de las leyes: el Estado liberal. De ahí los debates y las reconfiguraciones de la monarquía parlamentaria británica y la aparición de los partidos whig y tory como mecanismos de agregación de preferencias políticas mediante el nexo elección/representación política que permitieran formar mayorías y así tomar decisiones legitimas. Precisamente porque el nuevo poder político se alza como una amenaza potencial frente a la sociedad civil (ahora desprovista de poder alguno), los nuevos sectores sociales emergentes promueven cambios de vasto alcance; entre otros: los reyes deben acatar las leyes del parlamento, los impuestos necesitan el consentimiento de las cámaras legislativas, el derecho garantiza el respeto a la propiedad de la burguesía, el ejército ya no es del rey sino que deviene nacional y controlado por el parlamento, el parlamento es nombrado por elecciones libres y censitarias, y se amplían los derechos de expresión, reunión y asociación. Este proceso se realiza en distintos momentos históricos y con éxito muy desigual en el Reino Unido (s. XVII), en Francia con la II República (1850), o en la Alemania de la República de Weimar (19181833). Analicemos los principales ejes de este proceso.

El primer eje de la construcción de los Estados es el de los conflictos y procesos de democratización/des-democratización: en este orden de cosas las trayectorias tampoco son lineales, sino que poseen avances y retrocesos diferenciados en cada país; tampoco son ni simultáneas ni homogéneas, mutando extraordinariamente de caso a caso. Un factor decisivo en la democratización es la capacidad relativa de cada Estado, esto es, su eficacia a la hora de hacer cumplir las decisiones políticas que adopta. Estamos ante una dimensión clave, toda vez que la capacidad relativa de un Estado radica 
en el nivel y la intensidad con que la actuación de los agentes estatales afectan de modo más o menos significativo a la distribución de los recursos y poder, a las actividades y conexiones interpersonales existentes en un determinado territorio (Tilly 2007). Sin embargo, una alta capacidad puede estar al servicio de procesos de autoritarismo tanto como de democratización pero, en todo caso, ninguna democracia real es posible sin una efectiva capacidad del Estado de hacer cumplir sus decisiones. De hecho, las democracias en Estados de baja capacidad suelen ser democracias fallidas, con proliferación de conflictos violentos, presencia de señores de la guerra, zonas amplias a las que no alcanza el poder del Estado y presencia de una multiplicidad caótica y descoordinada de actores políticos. Las investigaciones empíricas comparadas más solventes muestran que es la debilidad de los Estados, su baja capacidad, y no el conflicto étnico o nacionalista el factor que explica la violencia y la aparición de guerras civiles. Los Estados incapaces de imponer con eficacia las decisiones legítimas y sancionar el incumplimiento de la ley, de administrar e incorporar sus periferias territoriales o de proveer de servicios y bienes públicos básicos a sus poblaciones constituyen los más proclives a la crisis endémica y la guerra civil (Laitin 2007).

El segundo eje del proceso de construcción de los Estados que debe examinarse es la cuestión de la Nación, la producción de Estados-nacionales, esto es, de Estados al servicio de la cultura, lengua e intereses económicos de la nación mayoritaria en el territorio estatal. En un primer momento, la Nación se construye desde el Estado (lengua estándar, mitos y símbolos compartidos, historia nacional etc.) como refuerzo comunitario de la ciudadanía individual, legitimador del esfuerzo jurídico, fiscal y bélico exigido a las poblaciones. Más tarde, la creación de capitalismos de base estatal al hilo de la competencia y coordinación internacional entre grandes potencias, se tradujo en el reforzamiento del nacionalismo de Estado a finales del siglo XIX. En ambos casos, la identidad étnica nacional actúa como mecanismo psicológico cognitivo de reducción de complejidad e incertidumbre y contribuye de modo capital a la ubicación de los seres humanos en un sistema de Estados económica y militarmente competitivos. Este proceso de nacionalización de la ciudadanía de los Estados cristalizó políticamente de modo muy diverso en cada país, mediante la articulación específica, en cada caso y en cada momento histórico, de dos elementos: 1) una etnicidad (historia, cultura, valores, mitos, símbolos) políticamente elaborada con materiales heredados, seleccionados e inventados por intelectuales, líderes y partidos nacionalistas; y 2) unas expectativas e intereses económicos nacionales dominantes en el seno de un capitalismo competitivo internacional. La identidad nacional provee así de una especie de lente a través de la que se interpretan las preferencias y las expectativas de la maximización de las oportunidades de cada Estado, proveyendo: 1) los criterios 
específicos de común pertenencia nacional (lengua, historia, religión, "raza", territorio etc.); 2) la movilización política de esos factores diferenciales para la distinción clave nosotros/ellos, propio/ajeno, amigo/enemigo; y 3) articulando estos elementos compartidos y esta diferencia con las otras naciones (dentro o fuera de las fronteras del Estado) mediante una narrativa histórica y un complejo mítico-simbólico de pertenencia/exclusión. La identidad nacional -siempre políticamente creada, nunca natural- resulta previa a la defensa de intereses económicos nacionales, porque provee el criterio de lectura a través del que se interpretan estos últimos (Hale 2008). De este modo, el proceso de construcción del Estado liberal se dobla con el proceso de la construcción nacional: no es la Nación la que segrega un Estado propio, sino el Estado el que conforma su Nación. Es el Estado el que, en determinados casos, procesos y contextos, y no en otros, monopoliza el poder político como Estado-nación al tiempo que construye un Estado nacional, esto es, una comunidad más o menos homogénea con una misma cultura, lengua, historia, mitos y símbolos compartidos por la mayoría de los ciudadanos. También aquí algunos Estados (Francia) mostraron más capacidad de nacionalización de sus poblaciones que otros, los cuales, en sus trayectorias dispares de construcción como Estadosnacionales, mantuvieron o incentivaron una crecientemente activada estructura plurinacional (España, Reino Unido).

Los Estados crearon las naciones median un proceso lento, plural y desigual que, como mostro en su día Eugen Weber, requirieron una alta eficacia nacionalizadora, la cual, a su vez, depende de la propia capacidad relativa de cada Estado desplegada mediante políticas tales como, entre otros: 1) conscripción universal para el ejército, 2) escolarización obligatoria generalizada, 3) sistema nacional de transportes y de vías de comunicación, 4) un mercado nacional de trabajo etc. (Weber 1977). El Estado nacional, por lo tanto, reelabora las precondiciones étnico-nacionales y económicas en el seno de una determinada estructura de oportunidad política histórica más o menos favorable, aportando los recursos materiales y morales, la ideología nacionalista y el complejo mítico simbólico y lingüístico y su generalización cultural que alumbran o no, según los casos, la aparición de una conciencia nacional compartida por la mayoría de los ciudadanos o por el contrario, dan pábulo a un conflicto plurinacional con demandas varias de autogobierno o secesión por parte de algunos territorios.

El tercer eje del proceso de creación de los Estados es la creación de la economía y los "mercados nacionales", esto es, de un capitalismo con base estatal. Las revoluciones inglesa y francesa mostraron con claridad que los Estados nacionales desempeñaron un papel determinante en el ascenso de las nuevas clases burguesas y del capitalismo nacional, a la vez frente a las viejas clases nobiliarias en declive y el ascenso de las nuevas clases trabajadoras. Al mismo tiempo los Estados participaron muy activamente en dos aspectos 
claves de la construcción de los capitalismos y los mercados nacionales; a saber: 1) los procesos de colonización y 2) el apoyo diplomático (tratados) y militar (guerras) al comercio exterior, siempre en un contexto internacional de permanente competición en el sistema de Estados.

Los Estados crearon los mercados, y no a la inversa. La Revolución industrial en Inglaterra, por ejemplo, resultó facilitada por la sistemática intervención del Estado en la protección de los contratos y los derechos de propiedad, lo que se tradujo en una más eficiente organización y aseguramiento de los mercados. En concreto, fue especialmente la regulación de los derechos de propiedad por parte del Estado británico y no el laissez-faire del libre juego de los mercados el factor decisivo que redujo los costes de transacción y con ello las economías de escala, creando desde arriba mercados mas integrados y mayores niveles de especialización y productividad (North 1981). A su vez, el Parlamento soberano sirvió de aseguramiento clave de derechos y libertades que facilitaron la entrada de nuevas elites, más dinámicas y con ideas innovadoras (Mokyr 2009).

Este tipo de procesos se tradujo a su vez, en la paulatina creación de Estados reguladores, con una creciente intervención en la economía productiva, comercio, infraestructuras, legislación y expansión comercial internacional, política industrial, etc. en un escenario de competencia comercial y guerras. Guerras que demandaban recursos, creación de ejércitos bien armados y abastecidos, nuevo y costoso armamento, cobro de impuestos y desarrollo de las burocracias y producción industrial pesada a gran escala. Con el paso del tiempo, en al tránsito del siglo XIX al XX, y con el apoyo del Estado, los capitalismos nacionales se trasforman mediante procesos de concentración, centralización, monopolización y expansión internacional a través del comercio, del capital financiero, de la exportación de capital, de la formación de grupos multinacionales y, esto nunca no debe olvidarse, del colonialismo. Todo ello exacerbó la competencia entre capitales nacionales y extranjeros, promovió medidas proteccionistas por parte de los Estados y alentó la internacionalización del capital financiero, siempre al servicio del capitalismo nacional regulado por cada Estado. Nació así un capitalismo de neta impronta estatal y nacional, pero que se coordina y compite internacionalmente. Incluso cuando los Estados se implican en los carteles internacionales, lo hacen con el fin de regularlos protegiendo sus propios intereses y mantener el control del capital nacional. Este Estado regulador del capitalismo nacional alcanza su máxima expresión en los años 1930 con el keynesianismo. Ahora bien, el proyecto del capitalismo nacional regulado por y desde cada Estado requirió, a su vez, una reforzada legitimidad democrática, ausencia de conflictos internos y un apoyo de los consumidores y los trabajadores, lo que se tradujo en nuevas concesiones de derechos, salarios mejores y estímulos al consumo de masas. 
En suma, la regulación estatal resulta clave para entender la economía nacional. La pobreza o riqueza de los Estados no depende de la cultura (catolicismo o protestantismo, por ejemplo) o la geografía (Norte o Sur), sino, sobre todo, del diseño y el funcionamiento de las instituciones estatales. Así, el desarrollo económico resulta deudor de los avances tecnológicos y productivos, los cuales, a su vez, requieren la existencia de instituciones políticas inclusivas, esto es, centralizadas, pluralistas y abiertas que permitan el acceso de nuevos sectores sociales con ideas innovadoras. Por el contrario, donde predominan instituciones estatales extractivas -que concentran el poder en une exigua elite y fijan pocos límites al ejercicio del poder de la misma- las elites extraen masivamente recursos del resto de la sociedad, mantienen niveles inaceptables de desigualdad, levantan barreras al cambio y la modernización y restringen las novedades y el progreso. Este papel de fracturar las barreras a la innovación y al crecimiento, mediante nuevos diseños institucionales abiertos, pluralistas y competitivos es el resultado capital a medio plazo de revoluciones como la inglesa o la francesa (Acemoglu \& Robinson 2012).

Solo a finales del siglo XIX las clases trabajadoras de los países más desarrollados comienzan a luchar de modo organizado y a conquistar determinados derechos políticos (sufragio universal, reunión, manifestación etc.) y sociales (huelga, limitación de horarios y mejora de condiciones de trabajo). La concentración del capital incentiva la organización de los trabajadores en partidos y sindicatos y aumenta, de este modo, su capacidad de presión sobre los Estados y las clases dominantes en demanda de mejoras sociales. Ahora bien, tal y como ocurrió con el proceso de democratización de los Estados, tampoco la aparición de los Estados de Bienestar surgió endógenamente de una evolución lineal de los Estados, sino como consecuencia de las luchas de clases entre capital y trabajo y la organización y movilización políticas de los trabajadores. De hecho, el Estado no creó desde arriba, la mayoría de las veces, los instrumentos de aseguramiento social, sino que su papel inicial consistió más bien en asumir, por distintas vías y soluciones institucionales, los sistemas de aseguramiento surgidos al hilo de aquellos conflictos y negociaciones entre capital y trabajo, haciéndolos obligatorios (Del Pino \& Rubio 2013). En Europa continental (Alemania, Francia, Bélgica, Países Bajos) y a diferencia de Estados Unidos, donde se adoptaron soluciones de mercado para establecer sistemas nacionales de aseguramiento, se crearon mutualidades laborales de seguro social que serían amparadas y extendidas desde el Estado, pero manteniendo su una relativa autonomía. En Reino Unido y los países nórdicos, por el contrario, se desarrollaría un modelo estatal de protección y aseguramiento universal de los trabajadores.

Por otra parte, los derechos sociales y la ciudadanía social, elementos constitutivos del Estado de Bienestar, resultan inseparables, en su génesis, 
de los procesos, autónomos y traslapados, de democratización y de aseguramiento de los derechos políticos, de consolidación y desarrollo de un capitalismo nacional (crecimiento de gasto público que resulta compatible con el crecimiento económico), así como de nacionalización de los Estados, y por lo tanto resultan deudores de una cierta lógica de desmercantilización de la condición cívica. Esta lógica compleja que superpone los procesos del bienestar, democratización, nacionalización y construcción de un capitalismo nacional, presenta una gran variedad en el tiempo y diferencias sustantivas entre los distintos países. Al respecto se han distinguido tres mundos del Estado de bienestar: 1) liberal: donde la gestión del bienestar se realiza desde el mercado y promueve niveles bajos de prestaciones y aseguramiento; 2) corporatista (bismarckiano o continental): donde las instituciones de aseguramiento son amparadas por el Estado, pero mantiene un amplio nivel de autonomía en la gestión de los programas, la desmercantilización es media y las prestaciones son altas, pero muy desiguales; y 3) socialdemócrata: con un alto nivel de desmercantilización y universalidad, que provee un nivel alto de prestaciones y muestra un importante componente igualitario (Esping Andersen 1990).

De esta suerte, en los años setenta y ochenta del siglo XX los Estados de Alemania, Francia, Austria, Bélgica o Países Bajos se configuraban como Estados de Bienestar caracterizados por: 1) obligatoriedad y generalización de aseguramiento (jubilación, salud y accidentes laborales, seguro de desempleo), basado en contribuciones procedentes de los salarios; 2) acceso al sistema mediante contribuciones de procedencia salarial; 3) financiación del mismo mediante cotizaciones sociales; 4) prestaciones en metálico; 5) estructuras burocráticas corporativas con participación del Estado y los agentes sociales; 6) nivel medio de desmercantilización; y 7) altos niveles de desigualdad entre insiders (trabajadores cualificados, funcionarios) y outsiders (mujeres, jóvenes, trabajadores no cualificados, inmigrantes).

En el proceso de creación de los Estados de Bienestar y su diversidad un factor clave reside en la muy diversa materialidad institucional del Estado, la cual restringe el abanico de posibilidades de acción a disposición de los partidos políticos y las elites. Así, la extensión de los Estados de Bienestar en los diferentes países no depende tanto de la cultura o las preferencias políticas como de la estructura institucional de la toma de decisiones: neocorporatista en Suecia o pluralista, en USA, por ejemplo (Steinmo 1993). Pero al mismo tiempo las preferencias, las creencias y las ideas resultan a menudo endógenas y no exógenas a las instituciones, esto es, se aprenden, se transmiten, pero también se contestan, toda vez que los actores no solo reproducen las instituciones, sino que las modifican. Los Estados no solo cambian por efecto de shocks externos (crisis económicas internacionales, guerras), sino mediante procesos endógenos de evolución, adaptación y conflicto (Steinmo 2010). Asimismo, 
el hecho de que la asistencia sanitaria en unos países se decantara por un sistema nacional y centralizado, mientras otros optaron por sistemas de seguros descentralizados y fragmentados, se explica por la presencia en cada país de puntos de veto que obligaban a negociar con los grupos de interés. Las reglas del juego -las específicas para la política sanitaria y las generales para todo el sistema político- incentivaron diferentes estrategias políticas para los actores en presencia, que condujeron a resultados divergentes (Immergut 1992).

Finalmente, como ya apuntamos con anterioridad, la lógica de los Estados es a la vez nacional e internacional, pues todos ellos interactúan en el seno de un Sistema de Estados. Por una parte, durante el siglo XIX y hasta muy avanzado el siglo XX (década de los ochenta), se produjo una progresiva intensificación de los procesos de colonización, de auge del comercio exterior, de internacionalización y de financiarización de la economía; por otra, la lógica que predominó no fue de globalización sino de nacionalización en sentido estricto. Y fue esta oleada de nacionalización, impulsada desde los Estados, la que condujo al auge de los nacionalismos de Estado, una lógica mundial competitiva entre capitalismos y Estados nacionales, que se tradujo en una escalada de enfrentamientos entre los Estados y, finalmente, en las dos llamadas Guerras mundiales.

Incluso en el período de posguerra y hasta los años ochenta del siglo $\mathrm{XX}$ nos encontramos con una lógica que, si bien adelanta algunos procesos de la posterior globalización, sin embargo, permanece deudora del sistema de competición/coordinación entre Estados y capitalismos nacionales. Breton Woods y la creación del FMI y el banco Mundial, constituye, en este sentido, no el inicio de una nueva lógica global desnacionalizadora de apertura a los mercados, sino la etapa final de coordinación internacional entre Estados y capitales nacionales. Este sistema reunía cuatro características fundamentales: 1) un gran protagonismo fiscal, gasto público creciente y decisivo papel regulador de los Estados (control estatal de las bolsas de valores y protección del sistema financiero nacional frente a las fluctuaciones internacionales); 2) control y supervisión de las tasas de cambio y los movimientos internacionales del capital y gestión económica interna destinada a proteger la economía nacional y, sobre todo, el pleno empleo en cada país frente de las perturbaciones internacionales. Esto es, los Estados participan en el ámbito multilateral internacional pero para proteger las economías nacionales; 3) la creación y fortalecimiento de un sistema multilateral que se realiza manteniendo y aun reforzando la gestión pública de la economía, mediante la reforma que no el desmantelamiento del Estado de Bienestar y la regulación del capital financiero y la banca; 4) hegemonía de la potencia económica mundial de los USA, a través de la dolarización de la economía mundial, que se traduce en un proceso de "americanización" más que de una verdadera globalización (Sasoon 2006). 
En definitiva, la creciente hegemonía del capital financiero no debe hacer olvidar que el sistema económico internacional de la época de Breton Woods resulta fundamentalmente controlado desde los Estados y es, por ello, muy distinto de la globalización neoliberal de los años 80 , deudora, como veremos a continuación, de parámetros muy diferentes.

\section{3. ¿Desaparición del Estado en la globalización o estatismo neoliberal autoritario?}

Desde la perspectiva estratégica y relacional que venimos empleando -en la que cada Estado constituye una cristalización de fuerzas, un conjunto conflictivo y disputado de legados varios de cultura política, estructuras institucionales y políticas públicas, que articulan de forma específica diversos regímenes de democracia y bienestar- se plantean varias cuestiones a la hora de explicar en qué medida los procesos de la globalización del siglo XXI y sus crisis afectan al Estado mismo. Pues, al fin y al cabo, de cada Estado concreto dependen, en ausencia de un orden internacional coactivo, los fracasos y logros históricos en los procesos de democratización y bienestar. Como hemos visto, en la materialidad institucional de todos y cada uno de los Estados se hallan inscritos los proyectos hegemónicos ganadores y las concesiones obtenidas mediante las luchas por la libertad, la democracia y el bienestar. ¿Se ha visto el Estado erosionado en sus funciones por los procesos de privatización, desregulación, la mercantilización y la dependencia de los flujos del capital financiero internacional, hasta el extremo de perder el lugar de escenario político, por excelencia, de los conflictos en torno a la democracia y la igualdad? ¿Están los Estados inexorablemente sujetos a la lógica y las políticas dictadas por el capital internacional? ¿Habrá de reemplazarse, en consecuencia, la propia noción de Estado por la de "Imperio" (Negri \& Hardt 2000), o la de Derecho por la de "Derecho global sin Estado"? (Teubner 1997).

Diversos estudios inciden en desmentir, con matices varios, la pérdida del carácter estratégico y funcional de los Estados, para subrayar su centralidad y capacidad adaptativa al nuevo contexto de la globalización (Robinson 2004, Slaughter 2004, Sassen 2006, Steinmo 2010, Jessop 2016). En este sentido debemos insistir, brevemente, en dos aspectos previos que resultan decisivos para evaluar el nuevo papel de los Estados en el mundo actual: 1) la globalización no constituye ni una lógica enteramente nueva (los Estados siempre estuvieron en mayor medida insertos en el mercado mundial), ni unitaria, universal y homogénea (se trata de un proceso desigual, contingente, irregular y multiforme). El resultado de ignorar esta complejidad espacial y esta continuidad/ descontinuidad en el tiempo es que se malinterpreten los 
procesos de globalización como un engañoso juego de suma cero: lo que ganan los "mercados" lo pierden "los Estados"; 2) frente a la divulgada tesis de la "convergencia" (de la neoliberal nivelación por abajo del bienestar en todos los países) debemos recordar que la globalización resulta procesada de modo adaptativo de forma muy diferente por los distintos Estados, dependiendo de sus legados institucionales y de políticas públicas, de su cultura política, de la correlación de fuerzas y las distintas coaliciones de partidos que los gobiernan.

Una vez aclarado lo anterior, sinteticemos algunos aspectos clave de la incidencia de la globalización sobre los Estados reguladores y de Bienestar del siglo XX: 1) la interdependencia económica y la formación de sistemas globales se implementan, muchas veces, desde los propios Estados y, muy especialmente desde un Estado particular: los USA (Panitch \& Gindin 2012). Ciertamente, el sistema de Estados ya no opera ni con el protagonismo ni con la autonomía previa a los años ochenta del siglo pasado, y se han acentuado los procesos de desterritorialización (que no "desnacionalización"). Pero lo nacional y lo global no son dimensiones mutuamente excluyentes: el mercado global requiere actuaciones y políticas nacionales. Son los Estados los que facilitan y participan de modo diverso en la génesis de los mercados globales y en el funcionamiento sin trabas de las empresas multinacionales. En suma, la globalización constituye un proceso en buena parte endógeno al Estado nacional (Sassen 2006); 2) la adaptación estatal a la globalización, mediante los (muy diferentes en cada país) procesos de mercantilización, desregulación y privatización, genera cambios en lo que afecta a la redistribución interna del poder político (división de poderes) en el ámbito estatal: el poder ejecutivo se impone claramente, en términos generales, al poder legislativo (y al judicial). Más que en términos de simple pérdida de poder estatal, por lo tanto, los cambios han de analizarse como deterioro de la calidad democrática y representativa de los Estados (Aman 2004, Mair 2013, Urbinati 2014); 3) hay algo más que mera desregulación en las reformas estructurales neoliberales: los procesos endógenos de los Estados implican, asimismo, una expansión de la esfera privada a costa de la esfera pública, no sólo en cuanto ampliación de la esfera privada a costa de la pública, y al hecho de que los mercados realicen funciones que antes correspondían al sector público (mercantilización de las funciones públicas), sino también a la progresiva inserción de intereses privados en al ámbito de las políticas públicas. Los mercados experimentan una ampliación de los bienes y servicios que regulan (y someten por lo tanto a la lógica del beneficio a corto plazo, a la desigualdad y al descuido de las "deseconomías externas"), e invaden funciones que correspondían al sector público y sus criterios democráticos de accountability. El Estado regulador y de Bienestar se convierte, no solo por razones globales sino propiamente endógenas, en Estado eficiente y competitivo para obtener la confianza de 
"los mercados", de tal suerte que la lógica del mercado global de capitales se instala en el núcleo mismo de la estatalidad. Esto implica que se erosiona no el "poder del Estado", ni tan sólo "el Estado de bienestar", sino algo aún más básico, las precondiciones mínimas exigibles para el normal funcionamiento de la democracia: limitación de la desigualdad, ciudadanía en sentido fuerte, información no distorsionada etc. (Brown 2015)

En definitiva, el Estado, o mejor, los Estados poseen una gran resiliencia y siguen desempeñando un papel político fundamental en la globalización. Incluso en su dimensión de Estados de Bienestar se muestran resistentes a las políticas de recortes, privatización y desmantelamiento. Ni el declinar indudable de su soporte electoral (la clase trabajadora organizada y cualificada), ni las "reformas estructurales" neoliberales intensivas que, desde luego, han causado cambios muy importantes, se han traducido en una liquidación pura y simple, acelerada e imparable del capital social de políticas públicas y arreglos institucionales de regulación y bienestar. Ni lo han hecho de modo uniforme y homogéneo en los distintos países. La dependencia de senda y los legados institucionales y culturales han motivado que los ciudadanos y las organizaciones previamente adaptados a los arreglos reguladores, han realizados tamañas inversiones en capital humano, institucional y financiero que vuelven los costes del cambio prohibitivos o, en cualquier caso, más altos que los costos de una relativa continuidad (Pierson 1994).

Los Estados de Bienestar han mostrado una muy desigual, adaptativa y autotransformadora capacidad, y su trayectoria ha dependido, en cada caso concreto, de la específica correlación de fuerzas, el perfil de la hegemonía política y los éxitos o fracasos de las luchas populares. El ámbito estatal conserva una función de escenario clave precisamente porque se transforma internamente para ubicarse en el fulcro de una nueva distribución de poderes sub y supranacionales, desempeñando un papel insustituible para la reproducción ampliada del capital. El declinar de las pretensiones de soberanía (siempre ideales, no se olvide) y la creciente dominación de la lógica del capital financiero, no debe extrapolarse en la tesis de una sociedad enteramente global en la que los Estados, frente a una supuesta "Edad de Oro" que nunca existió, desempeñan un papel decadente y periférico.

La existencia de poderosas tendencias desigualitarias de los Estados neoliberales no implica, en modo alguno, una homogenización o convergencia del capitalismo a escala mundial que aminore o torne irrelevantes las diferencias entre países. De hecho, la tendencia homogeneizadora de los mercados resulta contrarrestada por la contratendencia de "la política como fuente de diversidad" y los partidos políticos y sus coaliciones dominantes continúan ofertando y gobernando en cada país con políticas y programas alternativos, con resultados muy diferentes. El problema de las sociedades actuales es que 
los cambios estructurales de clase se traducen en preferencias más complejas y diferenciadas de los ciudadanos, lo cual pone de relieve la autonomía de la política y los procesos de producción de las preferencias, las identidades y los actores en cada Estado. Por otra parte, el espacio político del capitalismo actual es bidimensional, con un eje bien conocido que gira en torno a la mayor o menor regulación estatal de la economía, y otro, menos atendido, pero que se ha demostrado de gran relieve para la dimensión de la democracia y el bienestar, referido al balance entre las políticas públicas orientadas al consumo o a la inversión a medio y largo plazo, que afectan de modo diverso a las distintas clases sociales (Beramendi, Häusermann, Kitschelt \& Kriesi 2015).

El resultado de las políticas públicas del actual consenso en torno a las "reformas estructurales" no solamente consiste en el adelgazamiento del sector público o el refuerzo de la mercantilización, sino en la alteración del equilibrio político y de la correlación de fuerzas. El ocaso de los sindicatos, al hilo de la crisis, constituye un elemento clave del proceso. En efecto, los sindicatos, además de un papel económico de contrapoder en la regulación del mercado de trabajo (salarios, condiciones laborales) desempeñaron un papel político fundamental en la creación de otros actores, como los partidos Laboristas y socialdemócratas, los cuales, a su vez, influyeron en su día en las políticas públicas predistributivas y redistributivas del Estado de Bienestar, en confrontación con las pretensiones del capital. Es por ello que las políticas que restringen o eliminan la capacidad de los sindicatos de conseguir salarios decentes para los trabajadores, no solo generan una adicional trasferencia de rentas de los trabajadores hacia el capital, sino que reducen indirectamente la actividad sindical, debilitan a actores decisivos para la clase trabajadora y alteran la relación política de fuerzas en favor de la elites dominantes. En suma, las estrategias y las políticas de privatización hegemónicas en la crisis afectan a la distribución del poder político en el seno de los Estados, reforzando el dominio delas oligarquías, las cuales, a su vez, presionan para nuevas desregulaciones y privatizaciones.

El nuevo contexto global neoliberal ha revelado que políticas tradicionales del Estado de Bienestar se traducen ahora, con la emergencia del precariado, en la atención privilegiada a los sectores con empleo estable (insiders), y a la marginación de aquellos otros en situación precaria (tiempo parcial o empleo temporal) o en el paro (outsiders). Lo que tiene como consecuencia, de hecho, la adopción de políticas públicas menos igualitarias y el abandono de crecientes sectores del electorado disponibles para otras opciones partidarias (antipolítica, nacionalismos excluyentes, derecha radical xenófoba etc.). El dualismo del mercado de trabajo entre insiders y outsiders posee consecuencias capitales para las políticas públicas de bienestar. En efecto, este dualismo no solo implica una bifurcación que deja en la exclusión a amplios sectores, sino que cuestiona las 
políticas dominantes en muchos Estados contemporáneos de protección ex ante, las cuales, beneficiando a los sectores más privilegiados en el mercado de trabajo, derivan en políticas orientadas al consumo y facilitan la captura de rentas en el sector público. Por el contrario, las compensaciones ex post resultan claves para evitar el efecto excluyente y generador de desigualdad de oportunidades en el acceso al mercado de trabajo y potenciar las políticas orientadas a la inversión e innovación y las coaliciones políticas que las promueven (Rueda 2007).

La tensión y variación entre países de los procesos de estatalización y globalización puede analizarse como un conjunto de tendencias y contratendencias (Jessop 2016); entre las más relevantes podemos enumerar: 1) a la desnacionalización del Estado y la delegación de poderes hacia instancias supranacionales y sub nacionales, se contrapone una reacción de los Estados para controlar la dinámica multiescalar y aun la emergencia y refuerzo de nuevos nacionalismos de Estado o contra el Estado; 2) a la creciente tendencia a la gobernanza consensual y la privatización de áreas enteras de gobierno, se enfrenta la creciente presencia de coordinación, intervención y nuevo liderazgo por parte de los Estados; 3) frente a la progresiva internacionalización de las políticas públicas, la creación de alianzas y nuevos regímenes internacionales en defensa de intereses las grandes potencias y sus aliados.

Ya hemos referido que el proceso de globalización ha implicado no solo relativa desterritorialización, mercantilización y dominio del ejecutivo frente al legislativo. Además, una perspectiva estratégica y relacional del Estado requiere atención a los cambios en las relaciones de poder y las crisis de legitimidad democrática y representativa de los Estados. En este sentido, a los ejes institucionales y de actores que vertebraban de los Estados de bienestar: 1) El Estado regulador y sus mecanismos representativos y redistributivos, 2) los ciudadanos/as en cuanto clases trabajadoras en sentido amplio, los funcionarios, los jubilados etc. representados por partidos y sindicatos; debe añadirse la irrupción de un nuevo poder en procura de hegemonía: 3) la nueva constelación de actores nacionales e internacionales de los mercados financieros. El declinar de los sindicatos, de los acuerdos neocorporatistas, de la participación electoral y la ofensiva en favor de un nuevo consenso en las reformas neoliberales (desregulación, privatización), no se configuran como una evolución natural de los ciclos de la economía capitalista, sino como el resultado de una estrategia del poderoso actor que es el capital financiero, la cual altera, de modo diferente en cada Estado, los términos de la dialéctica tradicional capital/trabajo. Una constelación de empresas, trust, fondos varios de inversión, etc. impulsan una ofensiva coordinada -económica, política e ideológica- de privatización y desregulación de la economía a escala global. Una estrategia que, por cierto, encontró una muy desigual resistencia en cada país por parte de actores tradicionales como sindicatos y partidos socialdemócratas (Streeck 2014). 
Todo ello ha resultado en cambios no solo de las políticas económicas y de los arreglos institucionales de Bienestar, sino del propio tejido del capital social y organizativo de la sociedad civil, con el consiguiente declinar de las asociaciones cívicas y sindicales y la emergencia y refuerzo de muy poderosos grupos de interés (Skocpol 2003). Esta estrategia, debe atenderse tanto en sus objetivos -austeridad, desmantelamiento, desregulación, privatización- cuanto en los canales políticos de que sirve, pues se ejerce no solo a través de los votos y los partidos políticos dominantes, sino, también, mediante el más invisible mecanismo de los grupos de presión y su influencia fuera de la política electoral, una política de verdadero "combate organizado" como muestra el despegue de las cifras de dinero dedicadas al lobbying en Estados Unidos (Hacker \& Pierson 2010) y en la Unión Europea. Los grupos organizados poseen creciente capacidad de movilizar recursos económicos, comunicativos e intelectuales, y de coordinar de modo efectivo su actuación en múltiples niveles tanto estatales como internacionales.

Ahora bien, como se ha señalado, la política importa y, en cada Estado concreto, los diferentes partidos continúan ofreciendo un panorama no convergente desde el punto de vista ideológico de programas alternativos a los electores, por lo que el modelo explicativo de los cambios en curso debe orientarse más a dar cuenta del realineamiento y reestructuración del sistema de competición, que de una supuesta cartelización y desalineamiento generalizado (Thelen 2014).

En definitiva, la globalización neoliberal resulta decisiva no tanto por liquidar al Estado sino por reformularlo y reconstruirlo antidemocráticamente. De hecho, este es el problema que enfrentamos en la actualidad: de ningún modo asistimos a un lineal proceso de desregulación, por el contrario, en los años 2000 aparece una nueva perspectiva de neo regulación por otros medios. El Mercado libre ("free market") ni ha existido nunca ni tampoco ahora en pleno proceso de mercantilización de nuestras sociedades; el Estado sigue creando, manteniendo y reproduciendo los mercados capitalistas (Reich 2015). Y con ello el neoliberalismo se distancia sin remedio del utópico ideario anarquista conservador del libertarianismo (Plant 2010). Es más, el Estado ha pasado de ser el objetivo de la ofensiva neoliberal a ser el instrumento de esta ofensiva de extensión de los mercados desregulados, de la privatización del sector público y del recorte de los derechos. Este nuevo y para algunos impensable estatismo neoliberal ("liberal neowelfarism", "liberal neoestatism"), atiende tanto a imponer internamente, mediante políticas públicas y reformas políticas y administrativas, la visión dominante de la austeridad y la privatización; cuanto externamente a la defensa de los intereses del capital nacional en el ámbito internacional (Schmidt 2013).

En conclusión, frente a apresurados certificados de defunción, todo lo expuesto nos devuelve al Estado y a los sistemas de Estados a su lugar de 
escenario político central, si bien crecientemente degradado, en el que se ventilan la luchas políticas claves para la democracia y la igualdad en nuestro tiempo. Para comprender la evolución del Estado en la era Global no resultan apropiadas, ni empírica y ni normativamente, visiones estatistas, imperiales o cosmopolitas. En efecto, en primer lugar, en un mundo de soberanías fragmentadas y compartidas, una teoría del Estado (y de la Nación) que mantenga los supuestos monistas y teológico-políticos del soberanismo resulta un anacrónico desvarío (Havercroft 2011, Cohen 2012). En segundo lugar, la teoría normativa/empírica que postula la aparición de una nueva forma de dominación postmoderna, el Imperio, diferente al Imperialismo clásico de los Estados, resulta prematura y desacertada, aún como mera tendencia. Ni existe un poder único, un sistema de dominación a escala global que vuelva irrelevantes los Estados, ni una estructura desterritorializada y atemporal del poder que carezca de capital ni centro estratégico (Panitch \& Gindin 2012). Tampoco vivimos en un estado de excepción permanente, bajo un modo de dominación que transita de la sociedad disciplinaria a la sociedad de control total por necesidad histórica inmanente (Negri \& Hardt 2001). En tercer lugar, la teoría de la gobernanza transnacional y el cosmopolitismo multinivel que requiere normativamente, a su vez, una constitución cosmopolita (Held 2010), no resulta tampoco apropiada para explicar los procesos en curso en el seno del sistema de Estados neoliberales desregulados y desdemocratizados no pese a, sino desde los propios gobiernos y sus "reformas estructurales". Finalmente, tampoco la multiplicación de las redes y plataformas informáticas ("The Stack"), con sus múltiples pretensiones verticales de soberanía sobre el mismo espacio, parece quer vayan a formar una suerte de global Nomos of the Cloud que, siguiendo un plan maestro y coordinado, vuelva irrelevantes políticamente los escenarios institucionales y las luchas políticas en los diferentes Estados (Bratton 2015)

Frente al quimérico estatismo soberanista clásico y la en exceso apresurada diagnosis posmoderna de la desnacionalización generalizada del Estado, una perspectiva neoinstitucionalista histórica (Steinmo 2010, Schmidt \& Thatcher 2013, Thelen 2014) y, a la vez, estratégica y relacional (Poulantzas 1978, Jessop 2016), que atienda a las luchas por la democracia y la igualdad, inscritas en la cambiante materialidad institucional del sistema neoliberal de Estados y su resiliencia, se presenta como alternativa explicativa más plausible para dar cuenta de las estructuras y actores presentes en la crisis económica y socioecológica, así como de los nuevos antagonismos nacionales e internacionales emergentes en el mundo de hoy. 


\section{Referencias bibliográficas:}

Aman, A. (2004) The Democratic Deficit, New York: New York U. Press.

Acemoglu, D. \& Robinson, J. (2012) Why Nations Fail, New York: Crown.

Bartolini, S. (2005) Restructuring Europe. Centre formation, system building, and political structuring between the nation state and the European Union, New York: Oxford U. Press.

Beramendi, P. Häusermann, Kitschelt \& Kriesi The Politics of Advanced Capitalism, Nerw York: CUP.

Bratton, B.H.(2015) The Stack. On software and sovereignty, Cambridge(Mass): MIT Press.

Brown, W. (2015) Undoing the Demos. Neoliberalism's Stealth Revolution, New York: Zone Books.

Cohen, J. L. (2012) Globalization and Sovereignty, New York: CUP.

Del Pino, E. \& Rubio, M.J. (eds) (2016) Los Estados de Bienestar en la encrucijada, Madrid: Tecnos.

Esping-Andersen, G. (1990) The Three Worlds of Welfare capitalism, Cambridge: Polity.

Hacker, \& Pierson (2010) Winner-take-all politics: how Washington made the rich richer-and turned its back on the middle class, New York: Simon and Schuster.

Hale, H. (2008) The Foundation of Ethnic Politics. Separatism of States an Nations in Eurasia and the world, Cambridge: CUP.

Havercroft, J. (2011) Captives of sovereignty, Cambridge: CUP.

Held, D. (2010) Cosmopolitanism, Cambridge: Polity.

Immergut, E. (1992) Health Politics: Interests and Institutions in Western Europe, New York: CUP.

Jessop, R. (2016) The State. Past, Present, Future, Cambridge: Polity.

Laitin, D. (2007) Nations-States and Violence, New York: Oxford U. Press.

Mair, P. (2013) Ruling the Void. The Hollowing of Western Democracy, London: Verso.

Mann, M. (1986, 1993) The Sources of Social Power Vols. I \& II, Cambridge: CUP.

Mokyr, J. (2009) The Enlightened Economy. Britain and the Industrial Revolution, London: Penguin.

North, D. (1981) Structure and Change in Economic History, New York: Norton.

Negri, A. \& Hardt, M. Empire, Cambridge (Mass): Harvard U. Press.

Panitch, L. \& Gindin, S. (2012) The Making of global capitalism, London: Verso. 
Pierson, P. (1994) Dismantling the welfare state? Reagan, Thatcher, and the politics of retrenchment, Cambridge: CUP.

Plant, R. (2010) The Neo-liberal state, New York: Oxford U. Press.

Poulantzas, N. (1978) L'État, le pouvoir, le socialisme, Paris: PUF.

Robinson, W. (2004) A Theory of Global Capitalism: production, class and state, Baltimore: Johns Hopkins.

Rokkan. S. (1999) State Formation, Nation-Building and Mass Politics in Europe, New York: Oxford U. Press.

Rueda, D. (2007) Social democracy inside out: partisanship and labour market policy in industrialized democracies, New York: Oxford U. Press.

Sassen S. (2006) Territory, Authority, Rights, Princeton: Princeton U. Press.

Schmidt, V. \& Thatcher, M. (2013) Resilient Liberalism in Europe's Political Economy, Cambridge: CUP.

Slaughter, A. (2004) The Real New World Order, Princeton: Princeton U. Press.

Steinmo, S. (1993) Taxation and Democracy, New Haven: Yale U. Press.

Steinmo, S. (2010) The Evolution of Modern States, New York: Cambridge U. Press.

Streeck, W. (2014) Buying Time. The Delayed Crisis of Democratic Capitalism, London: Verso.

Thelen, K. (2014) Varieties of Liberalization and the new Politics of Social Solidarity, New York: CUP.

Teubner, G. (ed.) (1997) Global Law without State, Aldershot: Darmouth.

Tilly, Ch. (2007) Democracy, Cambridge: CUP.

Urbinati, N. (2014) Democracy Desfigured, Cambridge (Mass): Harvard U. Press.

Weber, E. (1976) Peasants into Frenchmen, Stanford: Stanford U. Press. 
